\title{
The effect of lung consolidation, as determined by ultrasonography, on first-lactation milk production in Holstein dairy calves
}

\author{
T. R. Dunn, ${ }^{*}$ T. L. Ollivett,† D. L. Renaud, ${ }^{*}$ K. E. Leslie, ${ }^{*}$ S. J. LeBlanc, ${ }^{*}$ T. F. Duffield, ${ }^{*}$ and D. F. Kelton*1 \\ *Department of Population Medicine, University of Guelph, University of Guelph, Guelph, Ontario N1G 2W1 Canada \\ †Department of Medical Sciences, School of Veterinary Medicine, University of Wisconsin, Madison 53706
}

\begin{abstract}
Bovine respiratory disease (BRD) is a complex disease process and many reports emphasize the negative implications of clinical BRD in dairy calves. Early diagnosis can be difficult because of inconsistent or absent clinical signs; however, the use thoracic ultrasonography has the potential to improve detection of respiratory disease. Earlier detection of BRD may result in actions to improve calf welfare and production. The objective of this prospective cohort study was to determine if lung consolidation (LC) in young dairy calves influenced age at first calving (AFC), first-lactation milk production, and survival to the end of first lactation. A total of 215 female calves from 3 dairy herds in southwestern Ontario were enrolled and assessed weekly during their first $8 \mathrm{wk}$ of life for evidence of LC using thoracic ultrasonography (Ibex Pro, Loveland, CO). Consolidation was measured, using gridlines on the screen of the ultrasound, in the first 10 intercostal spaces on both sides of the thorax. Calves were considered LC positive if $\geq 3 \mathrm{~cm}$ of consolidated lung was present. Multivariable linear regression models were used to identify risk factors associated with AFC and first-lactation 305-d milk production. A survival analysis was conducted to determine differences in survival from enrolment until the end of first lactation between calves with and without consolidation. In the study population, the following calfhood conditions were detected: twins (4\%; $\mathrm{n}=8)$, diarrhea in the first $21 \mathrm{~d}$ of life $(31 \% ; \mathrm{n}=66)$, rib fractures $(7 \% ; \mathrm{n}=14)$, lung abscesses $(3 \% ; \mathrm{n}=$ $6)$, and at least one diagnosis of $\mathrm{LC}(57 \% ; \mathrm{n}=123)$. Overall, $7 \%(\mathrm{n}=15)$ of calves died, and $18 \%(\mathrm{n}=38)$ of animals were sold before the end of first lactation. The presence of LC, at least once in the first $8 \mathrm{wk}$ of life, did not influence AFC, but did result in a $525 \mathrm{~kg}$ (95\% confidence interval: -992.81 to -60.25 ) decrease in first-lactation 305-d milk production. No difference in survival was detected between LC groups. These re-
\end{abstract}

Received September 21, 2017.

Accepted January 23, 2018.

${ }^{1}$ Corresponding author: dkelton@uoguelph.ca sults indicate that LC during the first $56 \mathrm{~d}$ of life has a long-term effect on dairy calves, manifested as reduced milk production during first lactation.

Key words: bovine respiratory disease, milk production, thoracic ultrasound

\section{INTRODUCTION}

Bovine respiratory disease (BRD) is a complex, multifactorial disease process and early diagnosis can be difficult because of inconsistent or absent clinical signs (McGuirk, 2008). A wide range of bacteria and viruses interact with management, environment, and calf factors to cause BRD. It has been reported that $22 \%$ of dairy calves are treated for BRD before weaning, and almost $20 \%$ of those calves are treated more than once (Windeyer et al., 2014). Bovine respiratory disease in early life is associated with increased risk of mortality; decreased ADG, resulting in calves with BRD being 11 $\mathrm{kg}$ lighter at 6 mo compared with calves that did not have BRD; increased age at first calving (AFC); and reduced first-lactation milk production (van Der FelsKlerx et al., 2002; Stanton et al., 2012).

Clinical scoring systems have been developed to assist in the detection of BRD in dairy calves, but no gold standard currently exists. Specifically, the Wisconsin Calf Scoring Chart partitions respiratory disease signs into 5 categories: rectal temperature, cough, nasal discharge, ocular discharge, and ear position (McGuirk, 2008). Each category is assigned a score ranging from 0 to 3 based on specific criteria, and an overall score is tabulated; a calf with a score $\geq 5$ is considered clinically ill (McGuirk, 2008). In addition to the Wisconsin Calf Scoring System, a dichotomous scoring system, measuring similar clinical signs, has been developed (Love et al., 2014). Drawbacks related to these approaches in respiratory disease diagnosis include both the subjectivity of the scoring, and dependence on the presence of clinical signs.

Noninvasive diagnostic imaging techniques are available for determining the presence of BRD. Formal evaluation of thoracic ultrasonography (TUS) has yielded a sensitivity and specificity ranging from 79.4 to $94 \%$ and 
of 93.9 to $100 \%$, respectively, when BRD diagnosis was confirmed by postmortem examination, confirming the presence of consolidation (Rabeling et al., 1998; Buczinski et al., 2015; Ollivett et al., 2015). Thoracic lung ultrasound has been shown to be a quick, accurate, and practical approach for the diagnoses of subclinical BRD (Ollivett and Buczinski, 2016). Comparisons have been made between TUS and clinical scoring (Buczinski et al., 2015). Although both methods are imperfect, TUS has demonstrated a greater sensitivity and specificity compared with clinical scoring (Buczinski et al., 2015).

Research evaluating lasting effects of lung consolidation $(\mathbf{L C})$ on productivity of dairy animals is limited. Adams and Buczinski (2016) used a single TUS assessment on 3-mo-old Jersey heifers to determine the presence of LC. Calves with extensive LC or a lung abscess had a greater risk of being culled or dying, but no association was found between degree of LC and AFC. Teixeira et al. (2017) measured LC by TUS dichotomously in female calves at $60 \mathrm{~d}$ of age, and found no association with mortality in the first $350 \mathrm{~d}$ of life. However, calves that had LC were more likely to be removed from the herd between $305 \mathrm{~d}$ of age and first calving, and had reduced reproductive performance following first calving. No difference was detected in weekly average milk production in the first $3 \mathrm{mo}$ of lactation.

A gap in knowledge currently exists in the relationship between lung lesions in calves and medium- to long-term performance outcomes. We hypothesized that LC will negatively affect the dairy calf and have lasting effects, which will be detected in delayed calving age and decreased first-lactation milk production. Although the initial purpose of this research was to determine the efficacy of a novel BRD vaccine in calves (Ollivett, 2014), the objective of the present prospective cohort follow-up study was to determine if LC in young dairy calves influenced AFC, first-lactation milk production, and survival to the end of first lactation.

\section{MATERIALS AND METHODS}

\section{Preweaning Management}

Calves were raised on 3 separate dairy farms in southwestern Ontario, Canada, and enrolled between January and December 2012. Elora Dairy Research Center [herd $1, \mathrm{n}=150$ lactating cows, average first-lactation 305-d milk production $(\mathbf{3 0 5 M})=8,567 \pm 1,314 \mathrm{~kg}($ mean \pm $\mathrm{SD})$ ], a privately owned commercial dairy farm (herd 2 , $\mathrm{n}=650$ lactating cows, average $305 \mathrm{M}=8,595 \pm 1,541$ $\mathrm{kg}$ ), and Ponsonby Dairy Research Center (herd 3, $\mathrm{n}=$ 55 lactating cows, average $305 \mathrm{M}=9,028 \pm 1,053 \mathrm{~kg}$ ) were included in the study.
In herd 1 , calves were fed $4 \mathrm{~L}$ of single-source colostrum within $12 \mathrm{~h}$ of birth. Calves were housed either within individual stalls in an enclosed room or outside in individual hutches. Feeding management included feeding $6 \mathrm{~L}$ of whole unpasteurized milk daily until approximately 6 wk of age, when calves were gradually weaned and moved to group housing by 8 wk of age. Bull and heifer calves were housed together. Calves had access to calf starter and water beginning at $3 \mathrm{~d}$ of age.

In herd 2, $2 \mathrm{~L}$ of single-source colostrum was offered to calves within $30 \mathrm{~min}$ of birth, with an additional 4 $\mathrm{L}$ offered in 2 feedings over the $24 \mathrm{~h}$ after birth. Calves were fed $6 \mathrm{~L}$ of whole unpasteurized milk twice daily, and housed in individual pens. At 3 wk of age, calves were moved as a group into a pen containing 20 calves. Here, calves were fed $8 \mathrm{~L} / \mathrm{d}$ of whole unpasteurized milk via an automated feeder (DeLaval Canada, Peterborough, ON, Canada), and had access to free choice water. Calves had access to free choice starter from 3 d of age.

In herd 3, $4 \mathrm{~L}$ of single-source colostrum was fed to calves within $12 \mathrm{~h}$ of birth, followed by $2 \mathrm{~L}$ of whole unpasteurized milk fed twice daily. At approximately 8 wk of age, all calves were weaned. All calves were housed outdoors in individual hutches until weaning, when they were moved to group housing. Both water and calf starter were offered free choice beginning at 3 d of age.

Herds were visited 2 to 3 times weekly to ensure calves were enrolled twice weekly. Both male and female Holstein calves were enrolled between 3 and $6 \mathrm{~d}$ of age in a vaccine trial (Ollivett, 2014). Briefly, calves were assigned to 1 of 3 vaccine groups: an intranasal vaccine (Inforce 3, Zoetis, Florham Park, NJ), subcutaneous vaccine (Bovi-Shield Gold 5, Zoetis), or intranasal and subcutaneous saline (placebo). All calves were followed for 8 to 12 wk after enrolment; only female calves were followed postweaning.

\section{Ultrasonography and Health Data Collection}

Whole blood samples were collected to assess passive transfer of maternal antibodies, in 3- to 6-d-old calves by jugular venipuncture, using a 20-gauge, 1 -inch (2.54 $\mathrm{cm}$ ) hypodermic needle (BD Vacutainer Precision Glide, Becton Dickinson and Co., Franklin Lakes, NJ). Samples were collected into a sterile, plastic, commercial blood collection tube without anticoagulant (BD Vacutainer, Becton Dickinson and Co.) and stored on ice. Within 4 to $6 \mathrm{~h}$ of collection, serum was separated by centrifugation at $970 \times g$ for $15 \mathrm{~min}$ at approximately $20^{\circ} \mathrm{C}$. Serum total protein $(\mathbf{S T P})$ was analyzed with a digital Brix refractometer (Misco PA202X-003-105, Cleveland, $\mathrm{OH})$. 
A portable linear ultrasound set at a depth of $9 \mathrm{~cm}$, frequency of $6.2 \mathrm{MHz}$, and gain of $16 \mathrm{~dB}$ (Near $13 \mathrm{~dB}$; Far 36 dB; Ibex Pro; E. I. Medical, Loveland, CO) was used to perform TUS on calves weekly (Ollivett et al., 2015). A single researcher performed all TUS exams at each visit. The thorax of calves was not shaved or clipped before performing ultrasound examinations. Approximately $300 \mathrm{~mL}$ of $70 \%$ isopropyl alcohol was used as a transducing agent and was applied to the hair of the thorax (Ollivett et al., 2015). Both sides of the thorax were scanned, beginning dorsally at the level of the scapula in the 10th intercostal space (ICS), advancing cranially toward the right 1st ICS or the left 2nd ICS (Ollivett et al., 2015). This assessment was completed by holding the ultrasound probe parallel to the rib and advancing the probe from the dorsal to ventral aspect of the ICS, allowing for visualization of specific ultrasound landmarks (Ollivett et al., 2015). To view the lung adjacent to the right 4 th through 1st ICS and left 4th through 2nd ICS, the probe was placed between the forelimb and the body wall (Ollivett et al., 2015).

Clinical respiratory scoring (McGuirk, 2008) was performed at each visit. The respiratory scoring system assigned a score of $0-3$ to 5 different health parameters, including rectal temperature, nasal discharge, cough, and ocular discharge or ear position. After the individual parameters were assessed, the scores were totaled and could range from 0 to 12 . When both ocular discharge and ear position scored $>0$, only the highest score was included (McGuirk, 2008). Any calf with a score $>4$ was considered clinically ill (McGuirk, 2008).

For lung tissue to be considered normal (LC-), a hyperechoic line and reverberation artifact were required. These characteristics are indicative of a contrast between the high impedance of the thoracic body wall and the low impedance of normal lung tissue (Blond and Buczinski, 2009). In contrast, when consolidation was present $(\mathbf{L C}+)$ the lung appeared hypoechoic and both the bright white band at the pleural interface and reverberation artifact were absent. To measure the extent of LC, the 1-cm gridlines on the ultrasound screen were used. A digital voice recorder was used to record all observations, which were later manually transcribed into a database (Microsoft Access 2010, Microsoft Corp., Redmond, WA).

\section{Postweaning}

In herd 1, approximately 2 wk after weaning, calves were group housed in a naturally ventilated bedded pack barn and offered hay in addition to calf starter. Breeding began at approximately 13 mo of age using AI exclusively. After calving, cows were milked twice daily in a parlor and fed a TMR diet.

Calves in herd 2 were housed in a combination of freestall and bedded pack pens following weaning, and the calves' diet was composed of calf starter and hay. Beginning at 6 mo of age, heifers were fed the same diet as the lactating cows. Breeding began at approximately 12 mo of age, and heifers were bred using a combination of sexed semen and a herd bull. After calving, heifers were milked twice daily in a rotary parlor; at 10 DIM cows were milked 4 times daily in the same parlor for the remainder of the lactation.

In herd 3 , calves were moved into a bedded pack barn, attached to the lactating cow facility, 2 wk after weaning. Here, the calves were raised in groups and fed hay and calf starter. Heifers were bred, beginning at 13 mo of age, using AI. Following calving, cows were housed in a tiestall and milked twice daily using a pipeline milking system and fed a TMR diet.

\section{Statistical Analyses}

Farm records were obtained from the herds' computer software (DairyComp 305, VAS, Tulare, CA). Data retrieved from DairyComp included the date of first calving, postweaning diseases, postpartum diseases (metritis, retained placenta, ketosis, and mastitis), first-lactation milk production, and removal from the herd (date of sale or death). Age at removal and age at parturition were back calculated using birthdate and date of the event.

Continuous outcomes included AFC and completed 305M. Dichotomous variables for calf events included twin (yes $=1$, no $=0$ ), scour (fecal score in the first $21 \mathrm{~d}<3=0$, fecal score $=3$ during at least one exam in first $21 \mathrm{~d}=1), \mathrm{LC}[<3 \mathrm{~cm}$ of consolidated lung on all ultrasound examinations $=0(\mathrm{LC}-), 1$ or more examinations with $\geq 3 \mathrm{~cm}$ consolidated lung $=1(\mathrm{LC}+)$ ], dystocia (no assistance or easy pull $=0$, hard pull or surgical delivery $=1$ ), failure of passive transfer (STP $\geq 5.2 \mathrm{~g} / \mathrm{dL}=0, \mathrm{STP}<5.2 \mathrm{~g} / \mathrm{dL}=1$ ), rib (rib fracture not palpable or visible on ultrasound $=0$, rib fracture palpable or visible on ultrasound $=1$ ), abscess (regions in the lung that contained both fluid and well-defined hypoechoic areas; no $=0$, yes $=1$ ), and illness (ILL; respiratory score of $\leq 4=0$ or $>4=1$ ). The cutoff of $3 \mathrm{~cm}$ for LC was determined by selecting the value between the 90th and 95th percentiles of ultrasound consolidation in calves with any amount of consolidation in their first ultrasound examination.

All statistical analyses were conducted using a standard statistical package (Stata 14, StataCorp LLC, College Station, TX). Sample size was originally calcu- 
lated to satisfy requirements for the primary purpose of this study, which was to determine efficacy of a novel vaccine, and address short-term implications of respiratory disease (Ollivett, 2014). As the present study was completed as a follow-up to the original study, all female calves that underwent TUS in the original study were enrolled, and no further sample size calculations were made. The primary outcome of interest was $305 \mathrm{M}$, and all variables that resulted in $P<0.20$ in univariable linear regression were entered as main effects in a multivariable linear regression model. The variable ILL was not entered as a predictor variable in the models because $\mathrm{LC}$ was the predictor variable of interest, and ILL was considered to be an intervening variable. Manual backward stepwise elimination was used to refine the model to include only variables that were significant at the $P<0.05$ level. Prior to the final elimination of a variable, a change of $>20 \%$ of the estimates of all other variables was used to assess for confounding. A Shapiro-Wilk test and a Cook-Weisberg test were completed to test for normality and homoscedasticity of residuals, respectively. All plausible interactions were tested. Linearity of continuous predictor variables were tested using locally weighted regression. A model was built in the same manner to address the outcome AFC, and LC was forced into the model, regardless of significance, as this was the predictor variable of interest.

To address the secondary objective, a survival analysis was competed using a Cox proportional hazard ratio and a Kaplan-Meier survival estimate to assess the effect of LC on survival. Animals were censored when they left the herd regardless of reason (animals who were sold or died), or right censored when they completed their 305-d first lactation. To standardize first lactation production, animals were considered to have finished their first lactation at 305 DIM. Schoenfeld residuals were used to statistically test the assumption of proportional hazards.

\section{RESULTS}

A total of 215 female Holstein dairy calves were enrolled and followed forward in time. In the study population, the following calfhood conditions were detected: twins $(4 \% ; \mathrm{n}=8)$, diarrhea in the first $21 \mathrm{~d}$ of life $(31 \%$; $\mathrm{n}=66)$, rib fractures $(7 \% ; \mathrm{n}=14)$, lung abscesses $(3 \% ; \mathrm{n}=6)$, at least one diagnosis of ILL $(58 \%, \mathrm{n}=$ $124)$, and at least one diagnosis of LC ( $57 \% ; n=123)$. Distribution of consolidation detection by week of assessment is summarized in Figure 1. Consolidation was detected as early as the second assessment, indicating calves were developing consolidation as early as $12 \mathrm{~d}$ of age. Both consolidation and a positive clinical score was detected in $43 \%(\mathrm{n}=92)$ of calves. Death occurred in $2 \%(\mathrm{n}=4)$ of calves before $56 \mathrm{~d}$ of age; therefore, 211 calves remained for postweaning follow-up.

An AFC was retrieved for $88 \%(\mathrm{n}=183)$ of the animals, and was measured in months. No difference was observed in the odds of calving between $\mathrm{LC}+$ and LC- calves [odds ratio: 0.65 (95\% CI: 0.35 to 1.23 )]. In the final multivariable model, failure of passive transfer, vaccine type, and herd were significant and were therefore retained in the model (Table 1). No significant association was observed between LC and AFC ( $P$ $=0.553)$.

Complete lactation data were obtained for $66 \%$ ( $\mathrm{n}=$ 140) of animals, and average milk production for the study population was $8,626 \pm 1,427 \mathrm{~L}$ (mean $\pm \mathrm{SD}$ ). Age at first calving and $\mathrm{LC}$ were significant in the final multivariable model of $305 \mathrm{M}$ (Table 2). An increase in $305 \mathrm{M}$ of nearly $140 \mathrm{~kg}$ (95\% CI: 33 to $241 \mathrm{~kg} ; P=$ 0.01 ) was associated with a 1-mo increase in AFC. In contrast, LC+ was associated with a $525 \mathrm{~kg}$ (95\% CI: -993 to $-60 \mathrm{~kg} ; P=0.03)$ decrease in first-lactation milk production.

Overall, $7 \%(\mathrm{n}=15)$ of heifers died, and $18 \%(\mathrm{n}=38)$ of animals were sold before the end of first lactation. In the LC- group $5 \%$ of calves died, whereas $9 \%$ of LC+ calves died; however, this difference was not statistically significant $(P=0.33)$. There was no difference $(P$ $=0.42$ ) in the proportion of calves sold, with $15 \%$ of LC - and $20 \%$ of LC+ calves being sold before the end of first lactation. The hazard of leaving the herd before the end of first lactation was not significantly different between $\mathrm{LC}+$ and $\mathrm{LC}-$ calves [hazard ratio $=1.3 ; 95 \%$ CI (0.7 to 2); $P=0.368$; Figure 2].

\section{DISCUSSION}

The purpose of this study was to assess the effects of LC in young Holstein dairy heifers on their survival and first-lactation milk production. Thoracic ultrasonography was used to diagnose calves as having consolidation (LC+), using a cutoff of $3 \mathrm{~cm}$ of consolidated lung tissue. No difference was observed in AFC or survival until the end of first lactation between consolidation groups (Table 1; Figure 2). However, milk production was significantly lower in $\mathrm{LC}+$ calves.

Clinical respiratory scoring is a more common practice among veterinarians and dairy producers, and is less expensive than TUS because ultrasound equipment is not required. Using clinical signs alone may fail to identify lung lesions, which was shown to affect more than $60 \%$ of calves during the preweaning period in one herd (Ollivett and Buczinski, 2016). Given that only $43 \%$ of calves had both a clinical respiratory score and consolidation supplies further evidence that clinical scoring alone fails to identify all calves with consolida- 
Table 1. Multivariable linear regression model of the assessment of lung consolidation with age at first calving (mo of age) for 183 Holstein heifer calves in 3 herds in southwestern Ontario

\begin{tabular}{lcccc}
\hline Variable & Coefficient & SE & $P$-value & $95 \%$ CI \\
\hline Herd 1 $^{1}$ & Referent & & & \\
Herd 2 $^{2}$ & 0.47 & 0.46 & 0.30 & $-0.43,1.38$ \\
Herd 3 $^{3}$ & -1.16 & 0.67 & 0.09 & $-2.49,0.16$ \\
FPT $^{4}$ & -0.97 & 0.69 & 0.17 & $-2.34,0.40$ \\
Injectable vaccine $^{5}$ & Referent & & & \\
Intranasal vaccine $^{6}$ & 0.14 & 0.35 & 0.68 & $-0.54,0.82$ \\
Placebo vaccine $^{7}$ & -0.43 & 0.58 & 0.48 & $-1.57,0.74$ \\
Consolidation $^{8}$ & 0.20 & 0.34 & 0.55 & $-0.47,0.88$ \\
Intercept & 25.59 & 0.41 & $<0.01$ & $24.78,26.40$ \\
\hline
\end{tabular}

${ }^{1}$ Elora Dairy Research Center, Ontario, Canada.

${ }^{2}$ Commercial dairy in southwestern Ontario, Canada.

${ }^{3}$ Ponsonby Dairy Research Center, Ontario, Canada.

${ }^{4}$ Failure of passive transfer as identified by serum total protein $<5.2 \mathrm{mg} / \mathrm{dL}$.

${ }^{5}$ Injectable vaccine (Bovi-Shield Gold, Zoetis Canada, Kirkland, Quebec, Canada) $=2 \mathrm{~mL}$ of commercial multivalent vaccine against bovine respiratory syncytial virus, infectious bovine rhinotracheitis, parainfluenza virus-3, and bovine viral diarrhea administered to calves subcutaneously at 6 wk of age.

${ }^{6}$ Intranasal vaccine (Inforce 3, Zoetis Canada, Kirkland, Quebec, Canada) $=2 \mathrm{~mL}$ of commercial trivalent vaccine against bovine respiratory syncytial virus, infectious bovine rhinotracheitis, and parainfluenza virus-3 administered to calves 3 to $6 \mathrm{~d}$ of age.

${ }^{7}$ Placebo vaccine $=2 \mathrm{~mL}$ of sterile saline administered both intranasally and subcutaneously at 3 to $6 \mathrm{~d}$ of age and 6 wh of age.

${ }^{8} \geq 3 \mathrm{~cm}$ of lung consolidation in at least one ultrasound exam during the first $8 \mathrm{wk}$ of life.

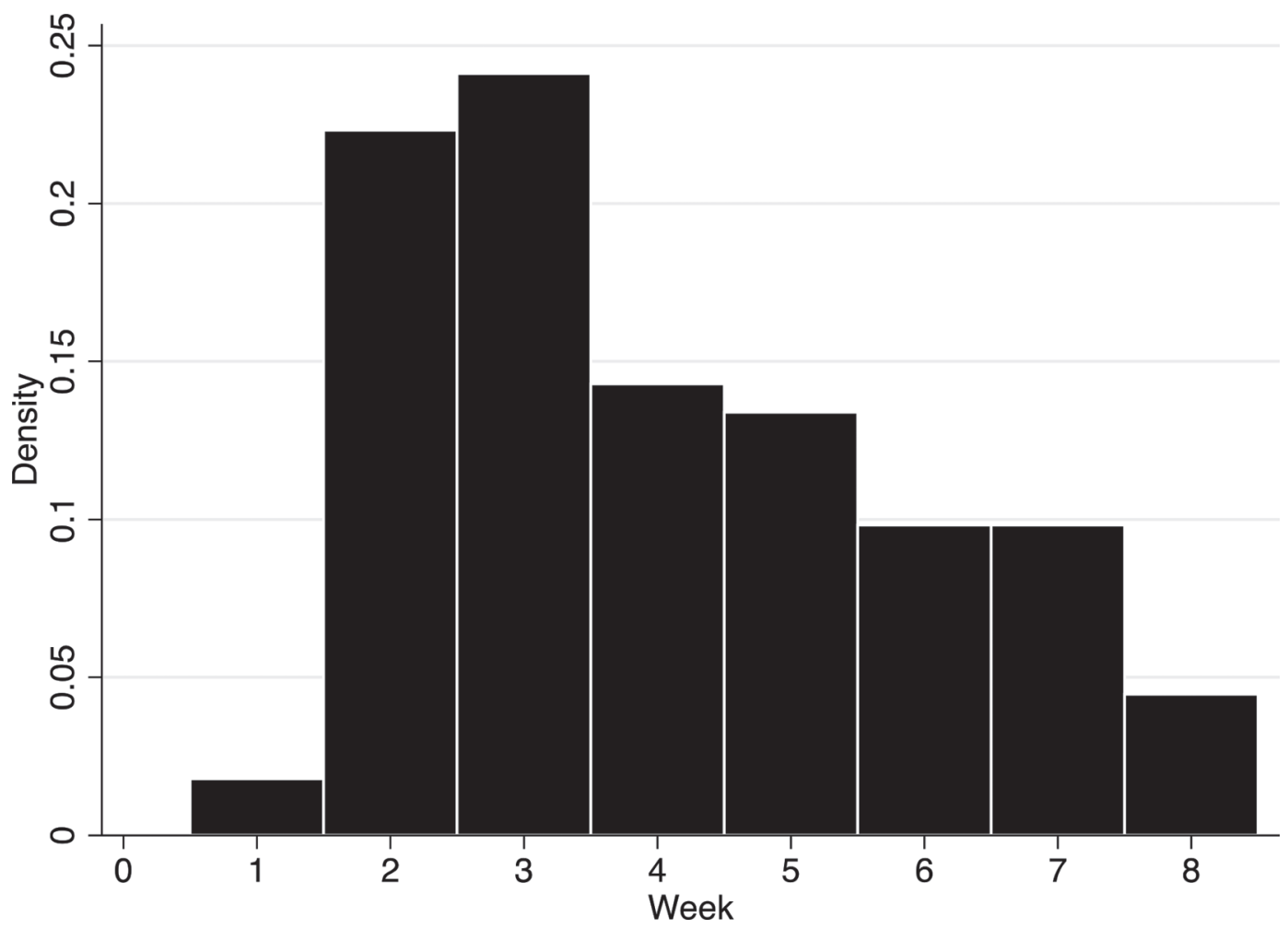

Figure 1. Frequency distribution of lung consolidation by assessment week in 123 female Holstein calves diagnosed with lung consolidation by thoracic ultrasound in the first $56 \mathrm{~d}$ of life. Lung scores were dichotomized to no consolidation $(<3 \mathrm{~cm}$ consolidation) or consolidation $(\geq 3$ cm consolidation). 


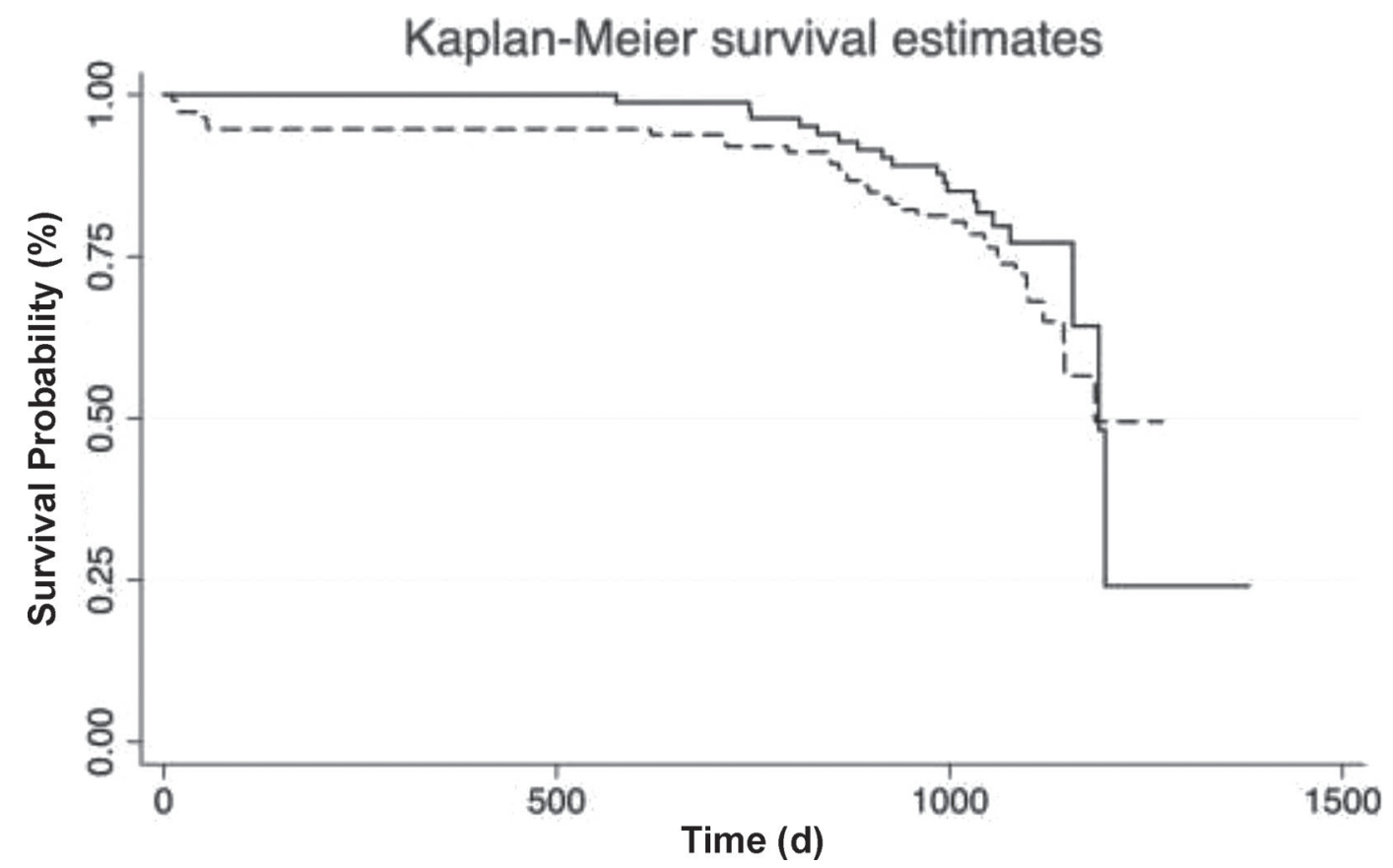

Figure 2. Kaplan-Meier survival analysis from enrolment to time of death or culling in 215 Holstein female calves that underwent thoracic ultrasound examinations weekly from birth until $8 \mathrm{wk}$ of age. Lung scores were dichotomized to no lung consolidation ( $<3 \mathrm{~cm}$ consolidation; solid line) or consolidation ( $>3 \mathrm{~cm}$ consolidation; dashed line). Heifers with ultrasonographic lung consolidation did not have a different hazard of leaving the herd compared with heifers with no consolidation (hazard ratio $=1.29 ; 95 \%$ CI: 0.74 to $2.26 ; P=0.37$ ).

tion. Results from the present study indicate that ultrasonographic lung lesions develop as early as $12 \mathrm{~d}$ of age (Figure 1) and have a long-term effect on the dairy calf. Early interventions may be warranted to try to mitigate the associated milk loss.

Compared with previous work, the prevalence of LC detected in this study is higher, potentially due to more frequent ultrasound examinations performed throughout the preweaning period. Performing only one TUS exam at weaning, or when calves leave custom rearing (Adams and Buczinski, 2016; Teixeira et al., 2017), is likely to underestimate the number of calves affected with LC during the preweaning period.

Contrary to expectations, LC in the first $8 \mathrm{wk}$ of life was not associated with an increase in AFC among those that calved. This finding agrees with that of Adams and Buczinski (2016), who also reported no association between LC and AFC. The inclusion of calves from only 3 herds may have influences observed results, and is a limitation to this study.

No differences were noted in survival between $\mathrm{LC}+$ animals and LC- animals; however, milk production in the first lactation differed between the 2 groups. This contrasts with previous results reported by Adams and Buczinski (2016) and Teixeira et al. (2017). Study design may have played a role in observed results because previous studies only took one measurement of LC around weaning. Another reason that milk production differences in this study may differ from previous work is complete first-lactation milk production data were used, and a small number of animals left the herds before the end of first lactation. Teixeira et al. (2017) used partial lactation data and found no difference in production. These apparently conflicting results may in fact be different manifestations of the same phenomenon. It is possible that in the Teixeira et al. (2017)

Table 2. Multivariable linear regression model of the association of lung consolidation with first-lactation milk production $(\mathrm{kg} / 305 \mathrm{~d})$ in 140 Holstein dairy calves in 3 herds in southwestern Ontario

\begin{tabular}{lrrrc}
\hline Variable & Coefficient & \multicolumn{1}{c}{$\mathrm{SE}$} & $P$-value & \multicolumn{1}{c}{$95 \%$ CI } \\
\hline Age at first calving (mo) & 137.12 & 52.53 & 0.01 & $33.25,240.98$ \\
Consolidation $^{1}$ & -526.53 & 235.80 & 0.03 & $-992.81,-60.25$ \\
Intercept $^{2}$ & $5,325.62$ & $1,358.28$ & $<0.01$ & $2,639.72,8,011.52$ \\
\hline
\end{tabular}

${ }^{1} \geq 3 \mathrm{~cm}$ of lung consolidation in at least one ultrasound exam during the first $8 \mathrm{wk}$ of life. 
study, the animals exhibiting effects related to early LC were culled from the herd early in first lactation, and therefore not able to express their decreased milk production, whereas a management decision made to retain all first-lactation animals until the end of their lactation allowed the animals in the current study to express the production loss. It is also important to note that no difference in milk production seen in past research may be related to differential misclassification bias. Because past research only took one measurement of LC, it is possible that some truly diseased calves were classified as healthy. This would have biased results toward the null, supporting the finding of no difference in milk production.

Currently, no gold standard exists for the diagnosis of respiratory disease. However, LC can be rapidly detected using the same portable ultrasound unit and linear probe that is used routinely for bovine reproductive examinations. The use of regular TUS exams by veterinarians should be considered, given the long-term implications seen in this study. This practice would allow for earlier and more accurate detection of BRD. Additionally, TUS may prove useful for troubleshooting poor heifer performance and to identify risk factors for respiratory complications. Because little is currently known about which treatments and management practices may be effective in reducing the incidence, severity, or duration of LC, it may be beneficial to conduct intervention studies in the future to determine if the lasting effects of LC can be mitigated.

\section{CONCLUSIONS}

Diagnosing LC in the first $56 \mathrm{~d}$ of life has a significant long-term effect on the calf, manifested as reduced milk production in first lactation. The regular use of calf-side TUS for diagnosis of LC should be considered, given the prevalence and lasting effects seen. Further research, with increased sample sizes and variation in housing and management strategies, should be conducted to confirm the findings of the present study. In addition, future research looking at methods to mitigate the effects of LC may be warranted.

\section{ACKNOWLEDGMENTS}

Financial support for the initial vaccine trial was provided by the Ontario Ministry of Agriculture, Food, and Rural Affairs (Canada) and Zoetis (Florham Park, NJ). Special thanks to the dairy producers for the kindness and assistance during the study period.

\section{REFERENCES}

Adams, E. A., and S. Buczinski. 2016. Short communication: Ultrasonographic assessment of lung consolidation postweaning and survival to the first lactation in dairy heifers. J. Dairy Sci. 99:14651470. https://doi.org/10.3168/jds.2015-10260.

Blond, L., and S. Buczinski. 2009. Basis of ultrasound imaging and the main artifacts in bovine medicine. Vet. Clin. North Am. Food Anim. Pract. 25:553-565. https://doi.org/10.1016/j.cvfa.2009.07 .002 .

Buczinski, S., T. Ollivett, and N. Dendukuri. 2015. Bayesian estimation of the accuracy of the calf respiratory scoring chart and ultrasonography for the diagnosis of bovine respiratory disease in pre-weaned dairy calves. Prev. Vet. Med. 119:227-231. https://doi .org/10.1016/j.prevetmed.2015.02.018.

Love, W. J., T. W. Lehenbauer, P. H. Kass, A. L. Van Eenennaam, and S. S. Aly. 2014. Development of a novel clinical scoring system for on-farm diagnosis of bovine respiratory disease in pre-weaned dairy calves. PeerJ 2:e238. https://doi.org/10.7717/peerj.238.

McGuirk, S. M. 2008. Disease management of dairy calves and heifers. Vet. Clin. North Am. Food Anim. Pract. 24:139-153. https://doi .org/10.1016/j.cvfa.2007.10.003.

Ollivett, T. 2014. Understanding the diagnosis and risk factors for respiratory disease in dairy calves. $\mathrm{PhD}$ thesis. Chapter 4, Department of Population Medicine, University of Guelph, Guelph, Ontario, Canada.

Ollivett, T. L., and S. Buczinski. 2016. On-farm use of ultrasonography for bovine respiratory disease. Vet. Clin. North Am. Food Anim. Pract. 32:19-35. https://doi.org/10.1016/j.cvfa.2015.09.001.

Ollivett, T. L., J. L. Caswell, D. V Nydam, T. Duffield, K. E. Leslie, J. Hewson, and D. Kelton. 2015. Thoracic ultrasonography and bronchoalveolar lavage fluid analysis in Holstein calves with subclinical lung lesions. J. Vet. Int. Med. 29:1728-1734. https://doi .org/10.1111/jvim.13605.

Rabeling, B., J. Rehage, D. Dopfer, and H. Scholz. 1998. Ultrasonographic findings in calves with respiratory disease. Vet. Rec. 143:468-471. https://doi.org/10.1136/vr.143.17.468.

Stanton, A. L., D. F. Kelton, S. J. LeBlanc, J. Wormuth, and K. E. Leslie. 2012. The effect of respiratory disease and a preventative antibiotic treatment on growth, survival, age at first calving, and milk production of dairy heifers. J. Dairy Sci. 95:4950-4960. https://doi.org/10.3168/jds.2011-5067.

Teixeira, A. G. V., J. A. A. Mcart, and R. C. Bicalho. 2017. Thoracic ultrasound assessment of lung consolidation at weaning in Holstein dairy heifers: Reproductive performance and survival. J. Dairy Sci. 100:2985-2991. https://doi.org/10.3168/jds.2016-12016.

van Der Fels-Klerx, H. J., H. W. Saatkamp, J. Verhoeff, and A. A. Dijkhuizen. 2002. Effects of bovine respiratory disease on the productivity of dairy heifers quantified by experts. Livest. Prod. Sci. 75:157-166. https://doi.org/10.1016/S0301-6226(01)00311-6.

Windeyer, M. C., K. E. Leslie, S. M. Godden, D. C. Hodgins, K. D. Lissemore, and S. J. LeBlanc. 2014. Factors associated with morbidity, mortality, and growth of dairy heifer calves up to 3 months of age. Prev. Vet. Med. 113:231-240. https://doi.org/10.1016/j .prevetmed.2013.10.019. 